\title{
Between Anthropology and Communication: Towards a General Theory of Recognition
}

\author{
Vinicio Busacchi \\ Associate Professor of Theoretical Philosophy \\ University of Cagliari \\ Via Is Mirrionis $1-09100$ \\ Cagliari, Italy \\ Salvatore Italia, Ph.D. \\ $\mathrm{PhD}$ in Theoretical Philosophy \\ University of Cagliari \\ Via Is Mirrionis $1-09100$ \\ Cagliari, Italy
}

\begin{abstract}
By defining recognition as a «vital human need», somehow Charles Taylor opened the way to a possible reexpression of the theme of recognition within a general theory having an anthropological-philosophical base. The fact that a similar root can even be found in other fundamental subsequent researches, such as in Habermas, Ricoeur and Honneth, which does not only reinforce this interpretative line, but rather it tends towards an interdisciplinary articulation. This is because in constructing their respective theories, these scholars give a varied or even different reference to disciplines such as psychology, sociology, and politics. Actually, the concept of recognition has been variously developed by these disciplines, for different reasons and in relation to different domains of application. But, the conceptual and theoretical camp is fragmented, heterogeneous, and even contradictory. This paper aims to investigate whether philosophy may be used at a theoretical level to nourish this important concept within sight of a new general theory which subsumes the contribution of psychology, sociology, and politics.
\end{abstract}

Keywords: recognition, anthropology, critical hermeneutics, methodology, emancipation.

\section{Introduction}

It is not by chance that, implicitly or explicitly, all major scientific or speculative works on recognition have been developed (1) with a certain, varied reference to psychology, sociology or politics of recognition and (2) with a basic reference to a specific anthropological-speculative conception - i.e. a conception of the human being articulated between anthropology and philosophy - able to thematise and implement this dimension. Charles Taylor defined recognition as a «vital human need», comparing and connecting recognition to what is vital and basic for human beings as humans. Jürgen Habermas developed his critical-social theory of communicative action by strongly connecting it to a philosophy of the human being with a psychical-social basis. In fact, his constant reference to the human intersubjective dimension - which reverberates powerfully in his theory - does not simply mirror Habermas' interest and involvement in sociological studies, but rather is a specific view on the human being's biological and psychological condition concerning our constitutional imperfection that makes us entirely dependent on each other from birth. Even when growing up we are similarly interdependent, because on leaving home and the family we need others in order to learn how to become persons in the public, social sphere (see Habermas, 2014). Paul Ricoeur's investigation on recognition follows a similar ratio; from the one side, he anchors his theoretical construction on a philosophy of the capable human being, and from the other, this philosophy has a psychological-speculative heart formulated between Hegelianism and Freudianism. Meanwhile, Axel Honneth references Mead's social psychology and Hegel's dialectics of recognition more explicitly than Ricoeur, defining an ethics of conflict, or better «a moral grammar of social conflicts», that "conceals" an attempt to draft a specific philosophy of recognition. 
However, as Ricoeur underlines, the current state of using recognition is unclear and paradoxical: not only «it is a fact that no theory of recognition worthy of the name exists in the way that one or more theories of knowledge exist» (Ricoeur, 2005, p. IX); but without a rule-governed polysemy referring to speculative uses of recognition a coherent philosophical discourse cannot be realised. For Ricoeur, to study, clarify and articulate such a polysemy is the first commitment for philosophy; and philosophy, here, has to begin from a non-philosophical level of research, describing and subsuming a first level of reflective theorisation from the polysemy of recognition in ordinary language, knowledge and use(s).

This ability of philosophy to work while moving from a non-speculative to a speculative level is the first aspect that qualifies it as a privileged discipline to be used in the development of a general theory of recognition that must subsume the specific uses of recognition in psychology, sociology and politics, and at the same time clearly mirror it, grounding it to an anthropological-speculative sufficiently flexible conception, i.e. not too speculative, culturally and ideologically "angled", and not too vague. This latter task which is justified and explained by the previously mentioned constitutive reference of theorists of recognition to anthropology requires another additional functionality that philosophy possesses.

Philosophy's conceptual flexibility and variety of methods and styles are due to its vast and diverse history; it is a composite with a general, methodological/procedural interest that may (1) be separated from its specific, doctrinal/traditional references and connectedness and (2) be freely used or applied in different domains and contexts. Among others, a critical-hermeneutical approach articulated between explanation and understanding seems able to perform coherently a similar "function" in a great range of areas (a) summarising the general-formal aspects of the anthropologies involved and (b) evaluating the concrete possibility of a comprehensive use of a generalised theory of recognition. Paul Ricœur's methodology offers a useful example of a critical hermeneutics that can easily be extracted and cut off from specific ideological-speculative bounds (see Busacchi, 2015). Ricœur's disposition to co-philosophise, his interdisciplinary attitude and the varied character of his speculative approach (moving from spiritualism to phenomenology and reflexive philosophy, from hermeneutics to linguistics and analytic philosophy, etc.) clearly reveals a strategy for a comprehensive approach able to overcome radical disciplinary limitations. Among the generalisable elements of Ricœur's speculative style and philosophy is the idea of a reflective movement from the non-philosophical level to the philosophical one, or from the nonspeculative to the speculative, in which the first level or moment indicates the cultural sphere (myths, symbols, poetic or narrative language, traditions, common sense, etc.), the social sphere (practical/moral/political social engagement and similar) and the scientific sphere, i.e. the sphere of the different sciences. Similarly, Habermas approaches the main epistemological interests (technical, practical and emancipatory interests), which are the basis of different disciplines, from a critical-general perspective aimed at a non-scientific (yet not defeatist) approach to each discipline, so to keep them in a broader, and not perspective angled, spectrum of rationality.

It is the specific passage through Ricoeur, Honneth and Habermas' sociology of recognition that particularly demonstrates the centrality of an anthropological view, as well as the simultaneous and equal role played by a critical sociology of communication for a general perspective on recognition with theoretical bases. However, first, coherently following the methodological movement from non-speculative to speculative, discussion of the speculative element will be preceded by an essential analysis of the specific, disciplinary uses of recognition in psychology, sociology and politics respectively.

\section{Recognition in psychology, sociology and politics}

The concept of recognition is used extensively, both theoretically and clinically, in psychology and psychiatry, psychoanalysis, psychopathology and psychotherapy. In cognitive psychology, the notion has a central function in research and therapies related to memory, cognition and intelligence. A 'recognition test' connects these three level of mental life to measure and evaluate the degree of intelligence and the ability to perceive, remember, identify, associate and so on. It is even used in psychiatry as an instrument for specific cases (for the diagnosis of dementia, for example). For many, the mind operates as a system or a 'black box' that re-elaborates external data and re-organises it (see Friedenberg Silverman, 2006). This is human information processing. Directly or indirectly connected with this area, or even with other disciplinary domains for example, psychiatry there are several important key terms in current use, such as face recognition, word-recognition, recall (which is a notion of use and meaning in comparison with recognition), and pattern recognition. 
In self-psychology and psychoanalytic psychopathology, the notion of recognition appears in relation to different uses and contexts. One of them is related to the mental process that allows an infant to self-recognise. Indeed, in studying the case of an infant's first recognition of himself or herself, psychoanalysts use the concept of primary integration (Winnicott), whereas the concept of self-recognition has a varied, transverse use through theoretical and therapeutic approaches. For example, it is used in relation to the question of face recognition. However, psychopathology does not only consider and treat the conscious or cognitive area, meaning it has a very different use of 'recognition' when referred to anxiety disorders or compulsive disorders. In these cases, the mechanisms that alternate, distort and modify the process of a normal or proper recognition have a direct, strong link with subjective psychological experience(s) and life history, and the spectrum of varieties is vast. For example, the difference between the problematic of recognition in papiliophobia compared to the problem of self-recognition in narcissistic personality disorder is very huge. In fact, if in the first case the problem of recognition has to do with the symbolical identification of the flight of butterflies with the inexorable occurrence of changes, in the second case the problem of recognition has to do with a person's grandiose sense of himself/herself, and he/she lacks the ability to recognise the falseness and exaggeration of his/her achievements and personal qualities.

Another different use can be found in psychoanalytic therapy. In fact, thanks to a theoretical, original, link with philosophy, the dynamism of transference-countertransference in the patient-analyst relationship has often been described as a kind of a therapeutic, social, dialectic of recognition.

The sociological theme of recognition is relatively recent, but it already has a widespread, varied and important application in relation to questions of ethnic identity, with respect to settlement disputes (political and social anthropology, anthropology of law), in the analysis of social systems and in the study of social conflicts.

It is the notion of interaction that is of initial, greater, significance, than 'recognition', which is a more recent notion. Interaction has been, and is, of central importance in studying social exchanges, social interaction, symbolic interaction, social psychology, integration, rule, and so on. Essentially, the work done by Talcott Parsons in developing his General theory of social action (1949) marked an important difference from the sociology involved with anthropological and ethnological research, namely in developing sociological research that has investigated the question of intersubjectivity and interrelation in terms of the behaviours, social behaviours and rituals revealing reciprocity. In this key area the work done by Marcel Mauss (Essai sur le don. Forme et raison de l'échange dans les sociétés archaïques, 1923-24) was the first and most important. And even today it constitutes a central reference in the study of the dynamics of recognition (in philosophy as in the narrower field of social theory). Among his most important contributions, he has brought the issue of reciprocity in the field of economic anthropology, where experts such as Marshall Sahlins (Stone Age Economics, 1972) transforms reciprocity in the means of measuring the change of social distance, and therefore the degree of integration and, in some way, the quality of the inter-relationships in a given, specific social reality.

Today, some notions connected to reciprocity are related to both the classical concept of interaction and the more contemporary concept of recognition. Among them, what certainly stands out is the concept of solidarity and reciprocal altruism, in reference to which Georg H. Mead's concept of symbolic interaction almost assumes the function of a connecting-term between interaction and reciprocity, and between philosophy and sociology. Social interaction is a subject that assumes strong sociological significance, especially in the study of group dynamics; but the determination of the forms of interaction is a prerequisite to understand fully the processes of interaction, or direct and indirect interaction (See Luhmann, 1995). Mead's Social Behaviourism, or, rather, his Symbolic Interactionism, postulates that the mind and the Self are social products and that language constitutes the place of their emergence; language is the medium through which the experience and the (social) reality can be formulated symbolically. A central element of symbolic interaction is the individual's ability to assume the other within oneself and to regulate their conduct from this perspective. Mead's conception, which is developed around his symbolic interactionism, is still a fundamental approach in studying the "dialectics" of experience, culture, emotion and behaviour in human interactions. External behaviour has its origins in the interior attitudes, but, at the same time, the internal attitude is an integral part of the external act. The individual's conduct is always explainable through the collective relational context, which is his/her specific social background. Society, in fact, is not simply anterior to the individual, but it is interiorised in him or her through the many series of experiences he/she has had during his/her entire course of life. The basis of common sense is always social interaction, as the meaning of my gesture only becomes clear in the reaction that it causes in the other. 
The fact that I can consciously objectify the meaning abstracting from the immediate reaction of the other allows me to universalise the meaning and to develop a specific, personal re-elaboration (on the backdrop of a general framework of reference which Mead calls the generalised other). Mead articulated his sociological research to both sides of philosophy and psychology, treating the phenomenon of interaction in a manner that proved strategic and productive for the subsequent scientific-speculative studies on recognition. It is not by chance that Mead's social psychology has been a common point of reference in Habermas, Honneth and Ricœur's research on social action and recognition. In this regard, even the concept of conflict with its transversal semantic, articulated between philosophy, sociology and social psychology constitutes a key concept. In philosophy, it has assumed a speculative importance through Hegel's phenomenology, whereas in sociology it has been transformed into a sociological paradigm by Karl Marx and then Georg Simmel.

Evaluating from a generalised perspective the development of sociological research is linked to recognition, we can say that it has moved over the decades from a polarisation on the philosophical-sociological theme of intersubjectivity and conflict to the sociological theme of interaction and communication, and from there to the sociological-ethical-political theme of reciprocity. In this process, social psychology has emerged as a central force and resource, able to serve sociology as well as philosophy by exercising a strategic function of interdisciplinary contact and mediation. Meanwhile, the notions of intersubjectivity/interaction and conflict have played an analogous mediatory role thanks to their interdisciplinary semantic structure, historically developed between philosophy, sociology and psychology.

Simon Thompson is right to describe in his 2006's The Political Theory of Recognition the recent rise of recognition as the direct expression of «a significant transformation of the landscape of politics» (Thompson, 2006, p. 1). After the end of the Second World War, life in Western countries was for more than two decades characterised politically by «the social democratic consensus» and socially by their ideas of identity and the realisation of one's personal identification with a specific social class or rule; however, more recently, the dynamics have changed. The collapse of the ideology of social consensus under the criticism of the New Left (which criticised its «repressive tolerance» that «granted a merely illusory freedom» [p. 2]) and the New Right (which argued «that the welfare state damaged economic efficiency and undermined personal freedom» $[i b$. $]$ ) has largely influenced citizens' conception and experience of self-realisation and political commitment. «Into this vacated space Thompson explains, so-called new social movements have emerged to present a novel sort of challenge to the politics of social democracy. The women's movement, peace movement, and green movement, which did not fit on the traditional political spectrum. A series of challenges has also emerged to the nation-state itself. These have included the politics of nationalist and sub-nationalist movements, movements of indigenous peoples, and struggles against colonialism. As a result, a new politics of multiculturalism has emerged» $(i b$.). We may find other interpretations that, like Thompson, re-conduct the rise of recognition to a political-social crisis, understood as a cipher of our contemporary time, connecting it to a kind of anthropological crisis about personal identity/identification and personal realisation. We may recall Marcel Hénaff's anthropological research, for example, within which it is not rare to find some social-critical and critical-speculative analysis, particularly in his recent papers. For instance, his introduction to the 2006 paper Anthropology of Gift Exchange and Social Recognition offers a perspective with an anthropological view combined with social-critical and philosophical analyses and reflections. In trying to interpret the current increase of the theme of recognition in theoretical research and public communication, he recalls first the common thesis that, beyond the typical demands for social justice (because of economical differences in treatment or because of social conflicts of other kinds), there is an increasing demand for recognition through social estimation on the basis of an increasing diversification of the aspects and forms of identity. This is due not only to social status and professional rules, but also to cultural or ethnic relatedness, sex or gender, age and physical handicaps. But why has this rise happened only now, and not previously? For Hénaff, the reason must be found within the aggrandisement in the homogenisation of cultural references, in the appraisal of personal choices and in the diversification of lifestyle that, on the one side, encourages one to reinvent the life and, on the other, to cut off all social elements of stability and continuity due to the transmission of traditional habits and rituals. A form of protective layer has now disappeared, and we face each other in a kind of social nudity. When we have such a vast variety of lifestyles, to the point that social conflict becomes easy and even our neighbours become like strangers, we end up constantly feeling socially undetermined, like individuals-in-general among other individuals-in-general. A great lack in recognition determines a tremendous need and an explicit demand for recognition, even in relation to those kinds of mutual consideration and help that was 'natural' to accomplish, like to support one's old or ill parent. 
This, now is not taken for granted, provoking a sense of disqualification and, consequently, a claim for recognition. For Hénaff, this explains why there is a pressing need to re-establish mutual trust. However, alongside this is an ideology of self-realisation or (like in neo-classic economics) the self-maximisation of one's personal identity and life, which does not accept any limitation or renouncement. The claim for respect and recognition tends to transcend cultural and traditional references, moving towards singularisation and depoliticisation. Paradoxically, these relativist projects of recognition and realisation demand recognition of all differences as being the same. Beyond all social expression of recognition, it is our dignity as human beings that is at stake, in Hénaff's perspective (see Hénaff 2006, 2010).

If for Thompson the theme of recognition has its reflective and argumentative source in politics and political theory, for Hénaff the root is anthropological. But anthropology must be exercised as or referred to as critical sociology and philosophy in order to achieve a comprehensive and deep understanding of this problem, and in order to find an exact function and usability of anthropology's expertise and knowledge. However, both Thompson and Hénaff fail to recognise the ambiguous and fragmented background of the use(s) of recognition within the political sphere(s), which, on the contrary, is discovered immediately through an analysis starting from a non-philosophical level. This is an interesting aspect: it is indicating that the use of recognition in politics, theory of politics, political anthropology and political philosophy is not a unified and representative notion, nor a notion semantically clearly determined and clarified in its polysemy.

It is true that, in political theory, the concept of recognition has only emerged since the 1990s, especially through the work of Charles Taylor (The Politics of Recognition, 1992), and it has caused immediate reverberations in the public debate. However, on political and legal grounds, the use of the concept of recognition has a longer, different history and referential function. In Criminal law, for example, it is used speaking of «enforcement of foreign judgment». In Civil law it is used to speak of "recognition of natural children" or "recognition of legal personality". This latter use - which runs in parallel with the idea of "recognition of a State" or Government in International law - determines a theoretical problematic of a specific kind, related to the dilemma of whether states or corporations can be considered as subjects of recognition in the proper sense. From one side, they do not act as collective actors - even if they are defined as so - because they lack what is required in acting as one, in namely a constitutive, stable and unified will and intention. From the other side, international relations are refocusing the problem by deepening the notion of relation, investigating it and making explicit its implications in a way that may offer a richer, normative and moral articulation, compared to the narrow legal use. It is true that there seems to be greater sensitiveness of scholars, theorists and experts around the moral aspects and implications of recognition, even in the varied and fragile field of international law. For example, Allen Buchanan in the 'Synopsis' of his book Justice, Legitimacy, and Self-Determination: Moral Foundations for International Law (2004), writes:

Many international relation theorists as well as international lawyers and diplomats say that whether a state grants recognition or withholds recognition from a new political entity created by secession is purely a political matter. This is false if it implies that a state's behavior in recognizing another entity as a state or refusing to do so is not subject to moral evaluation. Recognition is not morally neutral even though it is true that under current international law states have the right to grant or withhold recognition as they see fit (Buchanan, 2004, p. 3).

As Buchanan explains, to recognise or not recognise a state always has positive or negative implications in moral terms, independent from the fact that the act or process is addressed to a new entity or an existing state. In fact, «recognizing an entity as a legitimate state empowers certain persons, those who constitute its government, to wield coercive power over others, for better or worse». And «to participate without protest in a practice of recognition that empowers governments that engage in systematic violations of human rights is to be an accomplice to injustice». Therefore, «to know what criteria an entity must satisfy to warrant recognition as a legitimate state, we must know what values the international legal order should serve and what role the practice of recognition is to play in serving them. This requires a moral theory of international law» (ib.). Following this disciplinary and argumentative line of discourse, we understand that the concept of recognition is connected to and intertwined with a moral and normative dimension. Conversely, we understand that the normative component is constituted by the concept of recognition, whether or not one remains in the field of the law or moves into the social, ethical and political fields. 
Following the Kantian formulation on which the idea of universal human rights is based, we say that «to recognise the other» means considering the other depositary and bearer of your own universal rights, that is the bearer of «equal dignity and respect» ${ }^{1}$, and, depending on the case, of your same social, civil and legal rights and duties.

Without doubt, it certainly is this ethical line coming from theoretical studies on international law and international relations that a reflective philosophy may find in its course through the non-philosophical nature of recognition in law. The ethical perspective probably constitutes a parallel disciplinary bridge, together with the speculative-anthropological approach, that offers a key way to regulate the polysemy of recognition in political theory. However, this remains a hypothetical idea, because Thompson, different from what Buchanan does in the field of international law, does not make a strong and direct reference to the ethical dimension in summarising the political theory of recognition. Instead, he simply remains focused on the political dynamics. In fact, for him scholars like Taylor, Honneth and Nancy Fraser «believe that contemporary politics has seen a shift away from ideas of class, equality, economy and nation towards those of identity, difference, culture and ethnicity. They also believe that it is possible to understand this political transformation as the result of the rise of the politics of recognition» (Thompson, 2006, p. 3). Thompson considers the political field as an independent one, where all the other aspects and discursive dimensions enter without shaking its centrality and autonomy in approaching and treating recognition. We will see whether this is true or false, and practically-politically suitable/acceptable or not.

A philosophical approach on recognition with an anthropological and communicative base: a doubled speculative approach (Ricoeur and Habermas)

As stated earlier, Charles Taylor defined recognition as a «vital human need», comparing and connecting it to what is vital and basic for human beings as humans. In a similar way, it is our dignity as human beings that are at stake in Hénaff's perspective. At the same time, it has been shown above how fragmented is the conceptual and theoretical scope of the concept actually is. This section of the paper aims to develop the concept of recognition specifically at a theoretical level.

The concept of recognition has many different components that come from psychology, social theory, political theory, anthropology and even epistemology if we consider all the struggles of empirical realists against forms of metaphysical realism that forget the importance of recognition (at least a possibility of recognition) in order to consider the existence of truth in connection to what is real (see Parrini, 1998). What seems to be a basic feature of the mechanism of recognition is its link with the notion of intersubjectivity. To the extent that human intersubjectivity is a linguistic form of communication, recognition needs language in order to take place. This holds at least for humans. It is easy to imagine simpler forms of recognition in the animal world too, e.g. where they recognise their belonging to a herd. To do so, they use communication. Language is then a subset of communication that, by making use of symbols, has greater potential in terms of creative power. To be clear, and as Gambarara shows, in the animal world the absence of complex communicative abilities makes the organisation of groups (cooperative hunting by wolves, the ant's role in its group) dependent on strength and physical dimensions, and in general on physically perceivable features. Human groups are instead dependent on language as the organising mechanism of society, it being the logical engine of lying and imagination (see Gambarara, 2005). In fact, as far as communication creates structures that feed back into the social and individual lives of communicators (like herds or territories), language boosts this creative potential of communication, leading it to its maximum potential.

Linguistic communication is for example the means of criticising illegitimate powers and, simultaneously, the way to set up legitimate ones. While doing so, social actors refer to the shared meaning that participants in social interactions must share to first reach a mutual understanding, before then looking for an agreement. The identity of meanings comes from the union of expectations that subjects have about a phenomenon (see Habermas, ${ }^{1984, \text { pp. }}$ ${ }^{26-27)}$. To come to this first type of agreement, subjects need initially to recognise each other as subjects and to recognise the meaning that each other give to that phenomenon. In this way, the shared meaning arises when intersubjectivity and recognition have taken place. Meanings are neither outside nor inside the mind (prior to intersubjectivity); individuals find and create them by drawing close to each other.

1 This Kantian formulation, on which is based the idea of universal human rights, is accepted in the field of practical philosophy even by those who reject the category of 'recognition', although the latter is now firmly tied to the formula of «equal dignity and respect». One scholar who has built a theory on that conception is Thomas Scanlon (see Scanlon, 1998; Id., 2008). 
As Habermas underlines, this notion protects the autonomy of individuals together with the possibility they have to influence the process of meaning creation; at the same time, it put constraints on individuals because they do not have infinite ways to come to an understanding given that they have to consider the possible understanding of the partner in the interaction (see Habermas 1971).

If social order one that has been recognised as legitimate must be conceived of as emerging from processes of consensus about the interpretation of reality (phenomena and needs), the problem arises regarding where man can find the resources for coming to the same interpretation of reality (understanding) as a basis for developing a consensus. This consensus is possible because the individuals engaged in an interactive search for it share the same 'Lifeworld' (Lebenswelt), a reserve of meanings on which they have a 'previous agreement' made up of 'unquestioned certainties' that provide a 'backing' that, being constantly nourished by shared experiences and feed back on previous interpretations, absorbs the risk of a strong and insurmountable incommunicability, and subsequent disagreement (see Habermas, ${ }^{1988,}$ pp. 85-86). The Lifeworld cannot be completely thematised simultaneously, as this would give rise to the paradoxical situation in which speakers judge their perspective from any perspective. Rather, the Lifeworld constitutes a 'background' (Hintergrund) and a 'foreground' (Vordergrund). However, what belongs to each of them depends on the situation, the dynamics of which might make explicit something that before (or in a different situation) remained implicit and yet influences our understanding and acts. Each situation carries a section that is halfway between these two dimensions, it is the selected mitthematisiertes Wissen of what is relevant for the situation but only potentially possible to explicate (see Ibidem, pp. 86-93).

What has been said up to now by following Habermas' point of view should enlighten readers about at least two aspects: recognition is not a phenomenon that is exclusive to humans, yet it has greater importance for humans because of their stronger dependence on symbolic structures, thus on the language and communication that are the blocks of a symbolically shaped Lifeworld. Recognition is also present in the animal world which shows that the ontological dimension of the recognition principle is primarily of a biological nature, a demonstration of a vital, essential, interdependence among living beings. If animals' lives are improved (in quality and length, and so in terms of survival) by communication, humans are constitutively communicative beings. This means that their own features depend on an intersubjective and communicative process of social interaction in which they develop both society and their own personality. Self-formation is a process of socialisation; I recognise the other as having the possibility of taking my place, but I recognise him/her as someone different from me. This process of individualisation through socialisation is available only in a community; infants do not develop into persons until they do not come to intersubjectively shared meanings (see Ibidem, pp. 187-241). By means of interpretative performances, individuals can preserve and innovate culture, while the latter can serve as a resource for people's identity construction as something with which to identify or disavow themselves; they 'build' themselves by renewing and stabilising society or by using it as a negative pole for their own personality. If a person was only the product of a socialisation process which he/she undergoes, he/she would lose any reference to his/her self. Rather, each person is also determined by abilities, qualities and predispositions that come from genetics (see Habermas, 2001/2002, pp. 80-114; here p. 105). On entering a public space, individuals innovate by bringing new desires into the public sphere, where they can be seen and discussed. This innovation is particularly evident in modern societies, as characterised by deliberative democracy (mirroring their evolutionary degree of emancipation from traditions and religious pressures)2. The development of information technology is an example of the increasing power of symbolic-linguistic communication in our daily lives, an aspect that removes us further from the animal world. In fact, in virtual communication, the bodily side of communication that is pivotal in animal's non-linguistic form of communication is absent, with communication relying on symbolic means only. To better focus the point, we can consider the use of binary codes " 0 " and " 1 " in computer science to develop complex icons that users use to interact with others on opposite sides of the globe without even hearing their voice or seeing their face or seeing their characteristic handwriting.

2 Habermas sketches the history of the evolution of political forms mostly in Strukturwandel der Öffentlichkeit. Untersuchungen zu einer Kategorie der bürgerlichen Gesellschaft, Frankfurt a. M., Suhrkamp, 1962. An analysis of the characters of deliberative democracy is provided in Faktiztät und Geltung. Beiträge zu Diskurstheorie des Rechts und des demokratischen Rechtsstaats, Frankfurt a. M, Suhrkamp, 1992. 
The bodily dimension is absent, thus enhancing the freedom of communication from bodily means of influence or even coercion; users can also communicate using automatic systems that try to replicate human communication, so to make interaction more comfortable ${ }^{3}$. Notwithstanding this type of freedom, however, recognition does not lose its strength, despite being faded, by relying on neat interactions that do not leave space for shades of meaning.

The challenge that information technology faces every day seems to be the one to connect virtual communication to real communication by creating, as far as possible, opportunities for shades of meanings and the complexity of communication that happens in normal, real human interactions. In a short space of time, virtual communication has extended the scope of our social interactions, thus increasing the possibility of developing ourselves and of broadening the scope of our current and currently possible claims of recognition. Simplifying the access to different and still perspectivally unknown social or individual struggles, i.e. ideas and claims raised by both individuals and groups, opens up our scope of potentially recognisable claims of recognition. However, there is a price to pay for this achievement: virtual communication is subjected less to meaning shifts and flexibility, thus compressing the development of personality and simplifying the rise of social conflicts by easily polarising complex social or individual conflicts.

\section{A Metaphysical Detour}

Do claims of recognition exist before we become aware of them? The answer might be - in a realist tone - YES, as their existence comes in degrees. There is a degree where they exist in a state of unawareness; this is their existence stricto sensu. Over that, there is a degree where they are recognised by individual subjects only ${ }^{4}$; This is their private existence. However, when they are also recognised by different subjects they acquire a degree of reality that makes them stronger; they come into public existence, and information technology helps this process of leading them into public existence. What still must be determined is (1) the explanation of how claims of recognition come into public existence/awareness (i.e. the passage from stricto sensu to public existence through a private existence), and above all (2) whether stricto sensu and private existence constitute sufficient grounds in order to speak of recognition.

As per (1), it is true that to be publicly acknowledged they need to pass through our Lifeworld (which, it is worth repeating, is our cultural filter made up of shared meanings that constitute our form of life). Yet, what has still to be determined if it is possible to determine is the role of external forces and of the internal recognition filters that allow external pressure to filter through our Lifeworld (coming either from external Lifeworlds or from the subjective unconscious). If the scope of our Lifeworld is more comprehensive than individuals' awareness of it, the claims of recognition are vaster than that. Why? Because some individual's claims are still unconscious subjects, some of which are passively influencing their conscious life as pressures, or they are conscious but in a different Lifeworld than ours (still being external to the same extent as unconscious ones, i.e., only having a stricto sensu existence). In the same way, there are claims of recognition that are still external to our Lifeworld; some of them will probably become part of it, while others will probably never be known. Thus, to borrow and alter a famous Shakespeare quote (Hamlet, 1.5.167-8), there are more claims than our epistemic social and individual perspectives make it possible to recognise.

Through socialisation and current claims of recognition that the subject can identify as operating in his/her society, he/she can define and choose from the natural pressures he/she feels are emanating from its private side. Through his/her private side, he/she can choose which social influences are apt (or are not) to his/her own particular personality, so to identify himself/herself with some claims of recognition while refusing others. Further, through his/her socialised side, he/she is influenced in terms of his/her personal growth, feeding it back to his/her own natural-private desires (by restricting those judged as unacceptable). Then, through his/her private side, he/she can push new ideas into the social realm as new claims of recognition that travel from a stricto sensu existence to the public realm by passing through a private experience.

3 E.g. the use of captcha, a backronym for 'Completely Automated Public Turing test to tell Computers and Humans Apart' is a type of challenge-response test used in computing to determine whether or not the user is human.

4 See Ricoeur's interpretation of the psychoanalytic dialectic between conscious and unconscious as connected to the assessment of the subject as a person (Ricoeur, 1990). Ricoeur conceives this dialectics in intersubjective terms, against Freud's closed model in which this assessment and cohesion depends on an intrinsic autonomy and from an internal dynamism. 
From these new ideas, the social sphere can be innovated so to better meet the needs and interests of the individuals, and it can be improved by the ideas emerging from different cultures that claim recognition in our Lifeworld.

\section{Conclusion}

It has been shown that recognition depends on the one hand on pressures that can be named "claims of recognition" while on the other the effectiveness of recognition (its realisation) depends on internal recognition (with respect to the claims that are going to be evaluated).5 Recognition is thus a mechanism that relies on two poles (evaluation and the object of evaluation) and on a dynamic of act and potency, current and potential. This makes recognition 'open'; even if it can be influenced by persuasion or coercion, its dynamic is essentially open. This could connect the theme of an anthropology of recognition to a practical theory, where it could be inferred that the dynamics of recognition should be kept normatively free in order to keep the subject in the position of moral actor. However, the openness characterising the concept of recognition hinges it on the basically open anthropological core of the human being: its capability. This characterises the human in an open yet vague way, vagueness that is implicit in any attempt to make sense of the broad spectrum of human life, which is wide, complex and again open to different and new possibilities.

To keep track of what has been done in this paper, in the psychological dimension, for example, the notion of recognition may be linked to the mental process that makes a person able to recognise himself/herself. It has been shown that the inner psychological dimension is strictly related to language and sociality, and in so being it is dependent on recognition in a stronger sense. In the sociological dimension, recognition is more deeply linked to intersubjectivity. With reference to Mead's philosophy, it has been said that a central element of symbolic interaction is the individual's ability to assume the other within one self, and to regulate his/her conduct accordingly.

Individual conduct is always explainable through the collective relational context, which is his/her specific social environment. Society, in fact, is not simply anterior to the individual, but is interiorised by him/her through the many series of experiences he/she has during his/her entire course of life. Here, recognition has a double aspect: it connects the subject with society (by making him/her a subject to be recognised) and it connects society to the subject to the extent that society can potentially be changed by a subject who does not recognise it under certain conditions.

This explains the emergence on the political scene of new social movements like feminist movements, peace movements, sex or gender movements, green movements and others, which did not fit in the traditional political spectrum. Furthermore, recognition also plays a role on the political scene in international law, where it is related to the dilemma of whether states or corporations can be considered subjects of recognition in the proper sense. As Buchanan stresses, to recognise or not recognise a state always has positive or negative implications in moral terms, independent from the fact that the act or process is addressed to a new entity or an existing state.

As far as it concerns a political theory, it could be inferred that the dynamics of recognition must be saved normatively (by means of bureaucratic procedures). However, the formal possibility of recognition that can be allowed by an institutional system is empty without a social reality that feeds this institutional mechanism of recognition by filling it with real and concrete social struggles of recognition that want to ascend to the institutional and political level to be discussed and possibly solved. As Habermas shows, the social dimension is thus pivotal, not only for the psychological dimension but also for the political one; in a multicultural society we see every day social challenges that deal with the theme of recognition and that claim a political-juridical resolution. Here the problem is that if the political-juridical level aims at being universal, a multicultural society is rather characterised by many different and coexisting perspectives and claims that are often incompatible. Thus, the problem is how to universalise a matter that (being ethically imbued) cannot be easily universalised (see Habermas, 1996). Here, as in the case of the psychological dimension, the boundary between a political and social theme is feeble, yet it is the social dimension that is the trigger of political issues, just as the psychological dimension triggers the individual identity. Indeed, in the case of the inner subjective perspective, recognition deals with the dynamic of recognition and disavowal of the subject with respect to his/her social context (see Honneth, 1995).

5 The evaluative point of view can always be considered 'internal' with respect to the object of evaluation, regardless of its nature. 
Following this disciplinary and argumentative line of discourse, we understand that the chain connecting these three dimensions is tight, whit all three based on an anthropological level marked by language and, bottom line, communication. Recognition is thus connected to and intertwined with a practical dimension. If a moral theory of recognition could be drawn up, it should be focused on the importance of the internal recognition filters where all morality of the subject becomes visible and is discussed. Yet, this is not one of the objectives of this paper, whose aim was to look for the anthropological connector among the various uses of the notion of recognition. It has been found in the anthropological and metaphysical dimension of a human as a linguistic and communicative being that, due to its osmotic and open characterisation, is at the basis of it being a homme capable (Ricoeur).

As such, the subject can change its own identity-possibilities and political reality by recognising some claims instead of others. This is exactly what should normatively be safeguarded, e.g. the possibility for subjects and societies to change cultural pressure that otherwise would be conceived of as ideological (dogmatic and immutable). Being a homme capable is, thus, a presupposition of our social and private life, but it is something that has to be conquered every day, in both the public and private sphere.

If the point (2) above was still without an answer, now it can be said that claims of recognition may be based on stricto sensu or privately existing claims of recognition, but these two types are only negative grounds for real claims of recognition that only exist intersubjectively. This is because recognition is based on communication and intersubjectivity, and cannot exist without it. Based on such presuppositions, the general theory of recognition proposed here is able to explain how psychological, sociological and political approaches to recognition can coexist without being irreconcilable. This is possible if recognition is based on a concept of human being as homme capable that is vague, yet able to keep these three dimensions together in a coherent way. It is this vagueness, though, that allows such a theory to connect recognition to an ethological explanation of its role and function, and yet maintain an openness that allows for explaining the way in which, for example, information technology can increase (or decrease) the potential for the subject as an extension of the scope of claims for recognition as allowed by the social network.

\section{References}

Buchanan, A. (2004). Justice, Legitimacy, and Self-Determination: Moral Foundations for International Law, New York, Oxford University Press.

Busacchi, V. (2015). 'The Ricoeurian Way: Towards A Critical Hermeneutics for the Human and Social Sciences', in American International Journal of Social Sciences, 4 (2015), no. 6, pp. 82-88.

Friedenberg, J. - Silverman, G. (2006). Cognitive Science: An Introduction to the Study of Mind, Sage Publications.

Gambarara, D. (2005). Comunicazione, cognizione, socialità, in D. Gambarara - F. Ferretti (eds.), Comunicazione e scienza cognitiva, Roma-Bari, Laterza, pp. 191-235.

Habermas, J. (1962). Strukturwandel der Öffentlichkeit. Untersuchungen zu einer Kategorie der bürgerlichen Gesellschaft, Frankfurt a. M., Suhrkamp.

Habermas, J. - Luhmann, N. (1971). Theorie der Gesellschaft oder Sozialtechnologie. Was leistet die Systemforschung? Frankfurt a. M., Suhrkamp.

Habermas, J. (1984). Vorstudien und Ergänzugen zur Theorie des kommunikativen Handelns, Frankfurt a. M, Suhrkamp.

Habermas, J. (1988). Nachmetaphysisches Denken. Philosophische Aufsätze, Frankfurt a. M., Suhrkamp.

Habermas, J. (1992). Faktiztät und Geltung. Beiträge zu Diskurstheorie des Rechts und des demokratischen Rechtsstaats, Frankfurt a. M, Suhrkamp.

Habermas, J. (1996). Kampf um Anerkennung im demokratischen Rechtsstaat, Frankfurt a. M, Suhrkamp.

Habermas, J. (2001/2002). Die Zukunft der menschlichen Natur. Auf dem Weg zu einer liberalen Eugenik?, Frankfurt a. M., Suhrkamp, pp. 80-114.

Habermas, J. (2005). Zwischen Naturalismus und Religion, Frankfurt a. M., Suhrkamp, 2005 (speech delivered on the occasion of the conferment of the Kyoto Prize, November 11, 2014; previously published in Neue Zürcher Zeitung, December 11-12th 2004).

Hénaff, M. (2006, 2010). Anthropology of Gift Exchange and Social Recognition, Lecture presented at Berkeley, May 2, 2006 and Brown, May 3, 2010.

Honneth, A. (1995). The Struggle for Recognition: The Moral Grammar of Social Conflicts, Cambridge, Polity Press.

Luhmann, N. (1995). Social Systems, trans. by J. Bednarz, Jr. with D. Baecker, Stanford, Stanford University Press.

Parrini, P. (1998). Knowledge and Reality: Essay in Positive Philosophy, Dordrecht, Springer.

Ricoeur, P. (1990). Soi-même comme un autre, Paris, Editions de Seuil.

Ricoeur, P. (2005). The Course of Recognition, trans. by D. Pellauer, Cambridge, Harvard University Press.

Scanlon, Th. (1998). What We Owe to Each Other, Cambridge, Harvard University Press.

Scanlon, Th. (2008). Moral Dimensions: Permissibility, Meaning, Blame, Cambridge, Harvard University Press.

Thompson, S. (2006). The Political Theory of Recognition: A Critical Introduction, Cambridge, Polity Press. 